more significant topic in today's uni-

Minds Wide Shut: How the New versity where those who disagree,

Fundamentalism Divides Us, Gary

Saul Morson, Morton Schapiro, Princeton University Press, 202, pp. 289, \$28.00 hardcover.

\section{How Not to Save the University}

\section{Robert Weissberg}

Gary Saul Morson and Morton Schapiro's Minds Wide Shut advances an idea that surely must be an article of faith among academics: "When people are polarized and 'tribalized' honest disagreement becomes impossible." (xv) The authors call this intransigence regarding the validity of one's own views "fundamentalism." Moreover, the authors add, the need for honest disagreement extends to the political realm more generally-it's the essence of democracy. According to Morson and Schapiro, such dogmatism undermines the academy's core mission insofar as it oversimplifies complex questions and inhibits learning across fields. All in all, then, it's hard to imagine a even ever so slightly, with the reigning orthodoxies are shouted down, denied research funding, socially isolated and, in more than a few cases, removed from paid employment (or never employed to begin with).

Disorder acknowledged, the task the authors lay out is straightforward: first to understand today's ever-spreading fundamentalism and then to suggest remedies to reverse it. More specifically, "We need to cultivate the skills of self-questioning, recognizing our own limitations, and attentive listening to those who differ-all of which are necessary for respectful, productive dialogue." (xvii)

Obviously, a huge task, and even modest progress would be most welcome but, alas, Minds Wide Shut will disappoint those who seek answers. The authors are brilliant scholars (Morson in Slavic languages, Schapiro in economics), and the book abounds with erudite excursions into fascinating topics. But the authors avoid their mission until the very end, and then offer only platitudes. Hardly surprising, of course, given the gargantuan nature of the task. Still, if

Robert Weissberg is a professor of political science, emeritus, University of Illinois, Urbana, Illinois; rweissbe@illinois.edu. He last appeared in AQ in the spring of 2018 with "The Futility of Ideological Affirmative Action." 
one promises a cure, more should be forthcoming than bromides.

Chapter 3, "Divided We Stand: The Politics of Hate," illustrates this retreat from the book's stated mission via numerous scholarly digressions. Even for a well-read reader, the chapter's parade of notables and asides often confuses the central argument. Among the distinguished authors cited are Arthur Koestler, John Milton, John Stuart Mill, August Comte, Claude Lévi Strauss, Bronislaw Malinowski, Sigmund Freud, Francis Bacon, Charles Darwin, Karl Marx, Paul Ehrlich, Niall Ferguson, Leo Tolstoy, Vladimir Lenin, Edward Bellamy, George Elliot, Fyodor Dostoevsky, La Rochefoucauld, Aristophanes, and Eric Hoffer. In short, hardly a discussion for those with mediocre SAT English exam scores. Yet, despite all the words, no mention is made of the formidable issues regarding the legal definition of "hate" or demonstrating its existence as an unexpressed motive. Nor does this grandiloquent "tour de force" help navigate all the current campus hate-related controversies-safe spaces, trigger warnings, offensive speech, microaggressions and all the rest that undermine civil discourse.

The authors tend to focus on what famous people say, rather than what is happening on campus. Chapter 5,
"Search for Eternal Truths," is typical. The chapter begins with a wonderful tale about a rabbi and a clock and proceeds to a brief but learned discussion of language, Samuel Johnson, various biblical tales, a dollop of Shakespeare, Edward Gibbon, Alexander Pope, Sophocles and so on before arriving at a strangely misplaced question of “How Old is the World?" All great stuff for those (like myself) who thrive on intellectual candy, but thin gruel for those wanting a more civil university.

Other fascinating side trips completed, what's next? In the final chapter one senses that Morson and Schapiro really don't know. They again dwell on the evils of fundamentalism and note that this utopian mentality exists across the political spectrum, infusing fields as different as religion, literature, and politics, and betrays a disdain for learning and empiricism. All true, of course, but hardly what was promised. Now, with the book's end in sight we, hopefully, arrive at the solution? No such luck.

Here is what they offer. First, we must forswear the temptations of theoretical panaceas. Second, we must avoid extreme solutions and never forget that certainty is beyond even the most rigorous inquiry. This means accepting the trade-offs that mandate partial, often limited conclusions. Lastly, we must cultivate good 
judgment, though it is, admittedly, no easy task. Then come such advice tidbits as avoiding deductive theories in favor of taxonomies, favoring complexity over the simple, and keeping in mind that conclusions are always tentative. It all ends with a discussion of Anton Chekhov's Enemies.

Why the limp conclusion? Surely these eminent scholars realize that hectoring the fundamentalists who now dominate many universities is pointless. No doubt, these authors must personally know countless dogmatic true believers, and have tried to persuade them to repent, undoubtedly to no avail. So why not prescribe stronger medicine to cure toxic fundamentalism?

Let me suggest why the authors shy away from tough antidotes. The decline of civil discourse in the academy is not a matter of its denizens being ill-informed regarding the virtues of intellectual tolerance. The dogmatists know these arguments, but they reject them, so all of Morson and Schapiro's pleading is a waste of time. The fundamentalists just don't care about sifting and winnowing in the marketplace of ideas to find, however imperfectly, the Truth. They already know the Truth and so the era of finding it is gone. With mission accomplished, the task for these fundamentalists is propagating it to students and banishing those who disagree. From their Ivory Tower perspective of true believers, Morson and Schapiro's vision is a message comparable to teaching obsolete Ptolemaic astronomy.

But there is more to explaining this side-step, and the heresy that might have made Minds Wide Shut unpublishable by Princeton University Press. To be blunt, today's university is filled with strident ideologues who reject Morson and Schapiro's pleas. and their presence on campus is largely, though not entirely, due to the current diversity mania. This book would be unnecessary if universities never created "grievance studies" departments as the duplicitous shortcut to hiring more blacks, women, and those from other "underrepresented" populations.

The problem of dogmatic fundamentalism is not one of theoretical physicists silencing a geneticist who rejects the blank slate view of human nature. The scientist may disagree but he's not about to disrupt the lecture. Rather, his campus colleagues over in Black Studies, Women's Studies, or English who specialize in postmodern "theory" are the likely disrupters, and so if Morson and Schapiro were serious (and courageous) they could conclude their book with "fire the radical crazies," or, at the very 
least, insist on the imposition of universal scholarly standards. Of course, this means de-diversifying the university, a career-ending DOA suggestion (Schapiro is President of Northwestern University and certainly knows this harsh truth).

Proselytizing for intellectual give and take is futile when haranguing those who view the university as an instrument of radical political change. The message of this book should be "don't hire those who reject intellectual civility in the quest for a crackpot Utopia." Yes, this might result in less demographic diversity, but as Morson and Schapiro tell us, life is about trade-offs. If we want a campus where the wall separating advocacy and scholarship cannot be so easily breached, we should choose intellectual tolerance over diversity. It's that simple but, alas, that is not the message here. 